\title{
Parenteral $\mathrm{Na}_{2} \mathrm{~S}$, a fast-releasing $\mathrm{H}_{2} \mathrm{~S}$ donor, but not GYY4137, a slow-releasing $\mathrm{H}_{2} \mathrm{~S}$ donor, lowers blood pressure in rats*
}

\author{
Adrian Drapala ${ }^{1}$, Dominik Koszelewski², Lenka Tomasova ${ }^{1,3,4}$, Ryszard Ostaszewski², Marian \\ Grman', Karol Ondrias ${ }^{4}$ and Marcin Ufnal ${ }^{\bowtie}$ \\ 'Department of Experimental Physiology and Pathophysiology, Laboratory of Centre for Preclinical Research, Medical University of Warsaw, \\ Warsaw, Poland; 2Institute of Organic Chemistry, Polish Academy of Sciences, Warsaw, Poland; ${ }^{3}$ Department of Pharmacology and Toxicology, \\ Faculty of Pharmacy, Comenius University in Bratislava, Bratislava, Slovak Republic; 4 Institute of Clinical and Translational Research, Biomedical \\ Research Center, Slovak Academy of Sciences, Bratislava, Slovak Republic
}

Hydrogen sulfide $\left(\mathrm{H}_{2} \mathrm{~S}\right)$ is involved in blood pressure regulation. We evaluated hemodynamic effects of $\mathrm{Na}_{2} \mathrm{~S}$ and morpholin-4-ium (4-methoxyphenyl)(morpholino)phosphinodithioate (GYY4137), $\mathrm{H}_{2} \mathrm{~S}$ donors. GYY4137 is the most widely studied slow-releasing $\mathrm{H}_{2} \mathrm{~S}$ donor, however, its ability to release $\mathrm{H}_{2} \mathrm{~S}$ under physiological conditions is unclear. Hemodynamics were recorded in anaesthetized Wistar-Kyoto rats at baseline and after intravenous (IV) or intraperitoneal (IP) administration of either a vehicle ( $20 \%$ dimethyl sulfoxide), GYY4137 or $\mathrm{Na}_{2} \mathrm{~S}$. The stability of GYY4137 in buffers and in plasma was evaluated with nuclear magnetic resonance. The vehicle, as well as GYY4137, given IV did not affect mean arterial blood pressure (MABP), whereas $\mathrm{Na}_{2} \mathrm{~S}$ produced a significant decrease in MABP. Similarly, IP given $\mathrm{Na}_{2} \mathrm{~S}$, but not GYY4137, lowered MABP. In the buffers at pH of 7.4 and 5.5 and in rat plasma no reaction of GYY4137 was found during 18 hours of observation. In contrast, rapid decomposition of GYY4137 occurred in buffers at $\mathrm{pH}$ 2.0. In conclusion, parenteral GYY4137 does not exert a hemodynamic effect in Wistar-Kyoto rats. This seems to be due to the high stability of GYY4137 at physiological $\mathrm{pH}$. Therefore, it is likely that widely reported biological effects of GYY4137 are not $\mathrm{H}_{2} \mathrm{~S}$-dependent but may depend on GYY4137 itself. However, the $\mathrm{H}_{2} \mathrm{~S}$-dependent biological effects of GYY4137 may be expected in tissues characterized by low $\mathrm{pH}$.

Key words: hydrogen sulfide, $\mathrm{H}_{2} \mathrm{~S}$-donor, GYY4137, sodium sulfide, blood pressure, gaseous transmitter

Received: 18 March, 2017; revised: 25 April, 2017; accepted: 26 April, 2017; available on-line: 27 July, 2017

e-mail: mufnal@wum.edu.pl

*The preliminary results of the study were presented at "Kardiologia Eksperymentalna" meeting, Rynia 2016, Poland, and Experimental Biology 2017, Chicago, USA

Abbreviations: ANOVA, analysis of variance; $\mathrm{BP}$, blood pressure $\mathrm{BW}$, body weight; DCM, dichloromethane; DMSO, dimethyl sulfoxide; GYY4137, morpholin-4-ium (4-methoxyphenyl)(morpholino) phosphinodithioate; $H R$, heart rate; IP, intraperitoneal; IV, intravenous; MABP, mean arterial blood pressure; NMR, nuclear magnetic resonance; WKY, Wistar-Kyoto

\section{INTRODUCTION}

Hydrogen sulfide $\left(\mathrm{H}_{2} \mathrm{~S}\right)$ is a sulfur-based gaseous transmitter that exerts numerous biological effects. Accumulating evidence suggests that $\mathrm{H}_{2} \mathrm{~S}$ contributes to the control of the circulatory system (Meng et al., 2014, Sikora et al., 2014, Wallace \& Wang, 2015, Yoo et al., 2015, Tomasova et al., 2016).
$\mathrm{H}_{2} \mathrm{~S}$ donors are divided into fast and slow releasers based on their rate of $\mathrm{H}_{2} \mathrm{~S}$ release. The most widely used compounds to generate $\mathrm{H}_{2} \mathrm{~S}$ are $\mathrm{Na}_{2} \mathrm{~S}$ and $\mathrm{NaHS}$. These compounds dissociate rapidly in water leading to an instant formation of $\mathrm{H}_{2} \mathrm{~S}$. Parenteral administration of $\mathrm{Na}_{2} \mathrm{~S}$ or $\mathrm{NaHS}$ produces a rapid, but very short-lasting, increase in plasma sulfide levels (Shen et al., 2011; Wang, 2012). The latter hinders the use of the donors in chronic cardiovascular research. Therefore, several slow releasing $\mathrm{H}_{2} \mathrm{~S}$-donors were synthetized, such as morpholin-4-ium (4-methoxyphenyl)(morpholino)phosphinodithioate (GYY4137). However, only few studies evaluated its hemodynamic effects (Li et al., 2008; Wang et al., 2013) and there is some inconsistency with regard to GYY4137 ability to release $\mathrm{H}_{2} \mathrm{~S}$ under physiological conditions (Li et al., 2008; Lee et al., 2011; Park et al., 2013; Martelli et al., 2014; Feng et al., 2015; Lohninger et al., 2015).

In this study, we compared hemodynamic effects of $\mathrm{Na}_{2} \mathrm{~S}$ and GYY4137 in rats. Furthermore, we checked the stability of GYY4137 in buffers at various $\mathrm{pH}$ and in rat plasma to establish its $\mathrm{H}_{2} \mathrm{~S}$ releasing potential under physiological conditions.

\section{MATERIAL AND METHODS}

Animal studies. The experiments were carried out according to Directive 2010/63/EU and were approved by the Local Bioethical Committee. The animals were received from the Animal Breeding Department of the Medical University of Warsaw and housed in the Central Laboratory of Experimental Animals in group cages with access to standard laboratory chow and water ad libitum. The rats were maintained in a temperature- and humidity-controlled room with a 12/12-hour light-dark cycle.

We did the study on male, 18-20-weeks-old, normotensive Wistar-Kyoto rats (WKY). All measurements were performed under general anaesthesia with urethane (Sigma-Aldrich) given IP at a dose of $1.5 \mathrm{~g} / \mathrm{kg}$ of body weight $(\mathrm{BW})$. Before the measurements rats were implanted with a venous catheter and an arterial catheter connected to the Biopac MP 150 recording system (Biopac Systems, Goleta, USA) (Ufnal et al., 2008). The measurements started 60 minutes after the induction of anaesthesia.

The effect of intravenous and intraperitoneal administration of GYY4137 and $\mathbf{N a}_{2} \mathrm{~S}$. Hemodynamics were recorded 20 minutes at baseline and 90 min after (1) intravenous (IV) infusion of either $0.25 \mathrm{ml}$ of the vehicle $(20 \%$ dimethyl sulfoxide (DMSO) in $0.9 \%$ saline, 
controls) or the vehicle containing GYY4137 (SigmaAldrich) at a dose of $80 \mu \mathrm{mol} / \mathrm{kg} \mathrm{BW}$ or $\mathrm{Na}_{2} \mathrm{~S}$ (SigmaAldrich) at a dose of $80 \mu \mathrm{mol} / \mathrm{kg} \mathrm{BW}$, or GYY4137 (house) at a dose of $160 \mu \mathrm{mol} / \mathrm{kg} \mathrm{BW}$; (2) intraperitoneal (IP) infusion of the vehicle or the vehicle containing GYY4137 (Sigma-Aldrich) at a dose of $140 \mu \mathrm{mol} /$ $\mathrm{kg} \mathrm{BW}$ or $\mathrm{Na}_{2} \mathrm{~S}$ (Sigma-Aldrich) at a dose of $70 \mu \mathrm{mol} /$ $\mathrm{kg} \mathrm{BW}$. For evaluation of blood pressure (BP) and heart rate (HR) response within the series, the average over 5 -minute baseline was compared with the averages over 1 minute after infusions for the first $10 \mathrm{~min}$ of the experiment, and the average over 5-minute baseline was compared with the averages over 5 minutes after infusions for the whole experiment.

Data analysis and statistics. Mean arterial blood pressure (MABP) and heart rate (HR) were calculated on the BP tracing using AcqKnowledge 4.3.1 Biopac software (Biopac Systems, Goleta, USA). To evaluate MABP and HR response within the series baseline recordings were compared with recordings after administration of evaluated compounds using the analysis of variance (ANOVA) for repeated measures. Differences between the series were evaluated using ANOVA, followed by Tukey's post hoc test or t-test, where appropriate. The Kolmogorov-Smirnov test was used to test normality of the distribution. A value of two-sided $P<0.05$ was considered significant. Analyses were conducted using STATISTICA 12.0 (Stat Soft, Krakow, Poland).

Chemistry study on GYY4137. GYY4137 synthesis. GYY4137 compound was prepared following a slightly modified literature procedure (Li et al., 2008): the solution of morpholine (11.5 mmol (1g)) in dry dichloromethane (DCM) (5 ml) was added dropwise at ambient temperature to the solution of 2,4-bis(4methoxyphenyl)-2,4-dithioxo-1,3,2,4-dithiadiphosphetane Lawesson's reagent $(2.5 \mathrm{mmol}(1 \mathrm{~g}))$ in dry DCM $(10 \mathrm{ml})$ under argon. The reaction mixture was stirred at $20^{\circ} \mathrm{C}$ for 4 hrs under argon. The precipitated product was filtered off and washed several times with cold DCM. The product was isolated as white solid with $55 \%$ yield and was pure, as determined by nuclear magnetic resonance (NMR). The title compound was obtained as a 2:1 complex of GYY4137 and DCM. ${ }^{1} \mathrm{H}$ NMR $(400 \mathrm{MHz}$, acetone- $\left.\mathrm{D}_{6}\right) \delta 2.88(\mathrm{q}, J=6.0 \mathrm{~Hz}, 4 \mathrm{H}), 3.38(\mathrm{~m}, 4 \mathrm{H}), 3.50$ $(\mathrm{t}, J=6.0 \mathrm{~Hz}, 4 \mathrm{H}), 3.81(\mathrm{~s}, 3 \mathrm{H}), 3.93(\mathrm{~m}, 4 \mathrm{H}), 5.60(\mathrm{~s}$, DCM), 6.87 (dd, $J=3.0,9.0 \mathrm{~Hz}, 2 \mathrm{H}), 8.05$ (dd, $J=6.0,9.0$ $\mathrm{Hz}, 2 \mathrm{H}) ;{ }^{31} \mathrm{P} \mathrm{NMR}\left(162 \mathrm{MHz}\right.$, acetone- $\left.\mathrm{D}_{6}\right) \delta 90.4 ;{ }^{31} \mathrm{P}$ NMR (162 MHz, D $20 /$ dimethyl sulfoxide-D $) \delta 89.0$. ${ }^{1} \mathrm{H}$ and ${ }^{31} \mathrm{P}$ NMR data were in full accordance with those reported in the literature (Alexander et al., 2015), (Fig. 1).

Stability of GYY4137 in buffers and plasma. Stability studies were performed in PBS buffer $(100 \mathrm{mM})$ at different pHs: 7.4, 5.5 and 2.0, as well as in rat plasma. The pH 2.0 was reached by mixing $\mathrm{NaH}_{2} \mathrm{PO}_{4}(100 \mathrm{mM})$ with phosphoric acid. GYY4137 (house) was dissolved in dimethyl sulfoxide- $\mathrm{D}_{6}$ and added to the medium before measurement $(20 \% \mathrm{v} / \mathrm{v}$ DMSO). Samples of the GYY4137 solution $(26 \mathrm{mM})$ were measured immediately after adding to NMR tube and after 1 and $18 \mathrm{hrs}$. Throughout the entire experiment samples were stored at $36.6^{\circ} \mathrm{C}$.

Measurement of $\mathbf{H}_{2} \mathrm{~S}$ release. The generation of $\mathrm{H}_{2} \mathrm{~S}$ from $\mathrm{Na}_{2} \mathrm{~S} \times 9 \mathrm{H}_{2} \mathrm{O}$ (Sigma-Aldrich) or GYY4137 (SigmaAldrich) was determined by the DTNB (5,5'-Dithiobis(2nitrobenzoic acid) assay. Briefly, stock solutions of $70 \mu \mathrm{M} \mathrm{Na} 2 \mathrm{~S} \cdot 9 \mathrm{H}_{2} \mathrm{O}$ and $140 \mu \mathrm{M}$ GYY4137 in Tris/HCl
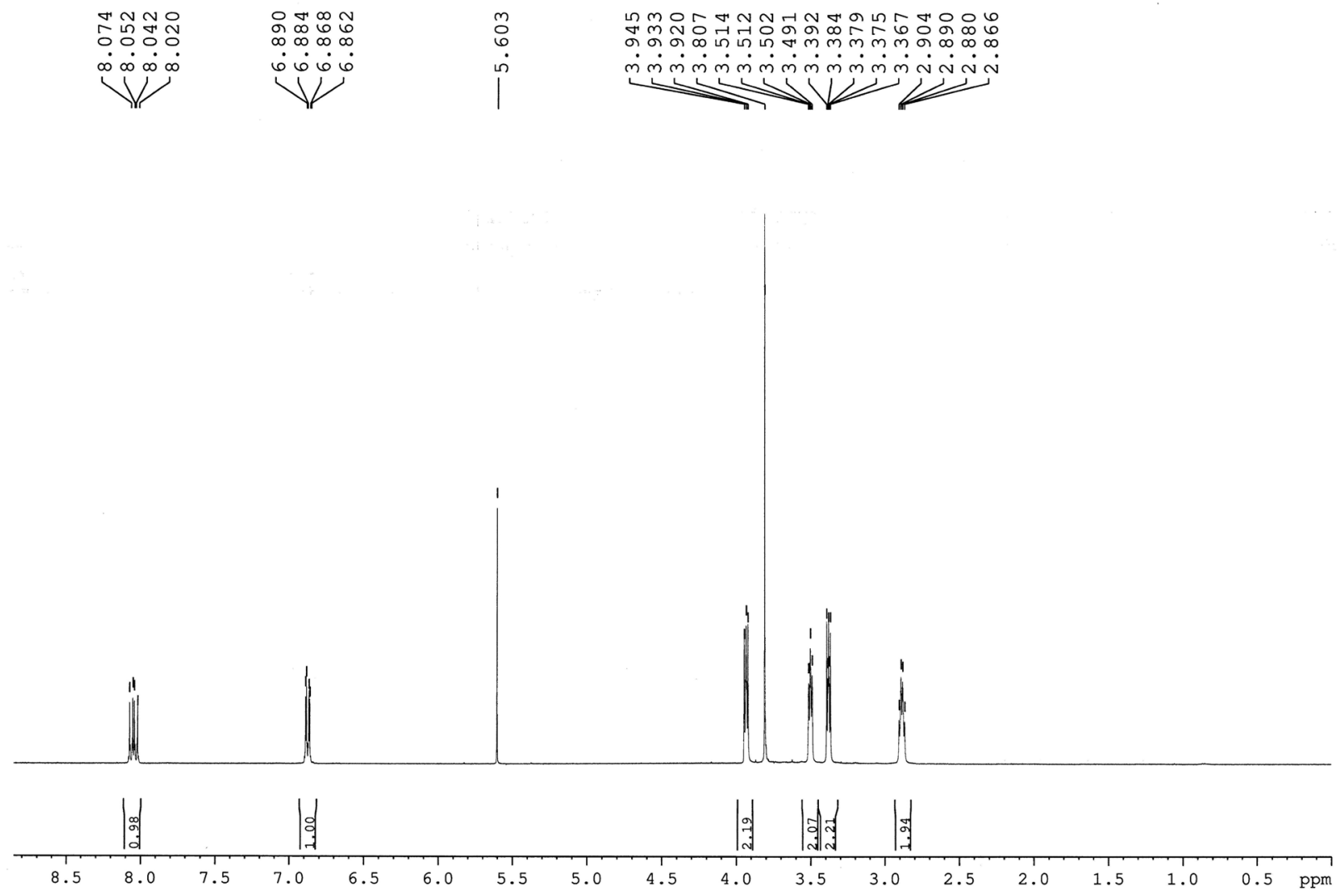

Figure 1. GYY4137 (morpholin-4-ium (4-methoxyphenyl)(morpholino)phosphinodithioate) ${ }^{1} \mathrm{H}$ NMR Spectrum (400 MHz; acetone- $\mathrm{D}_{6}$ ). 
A

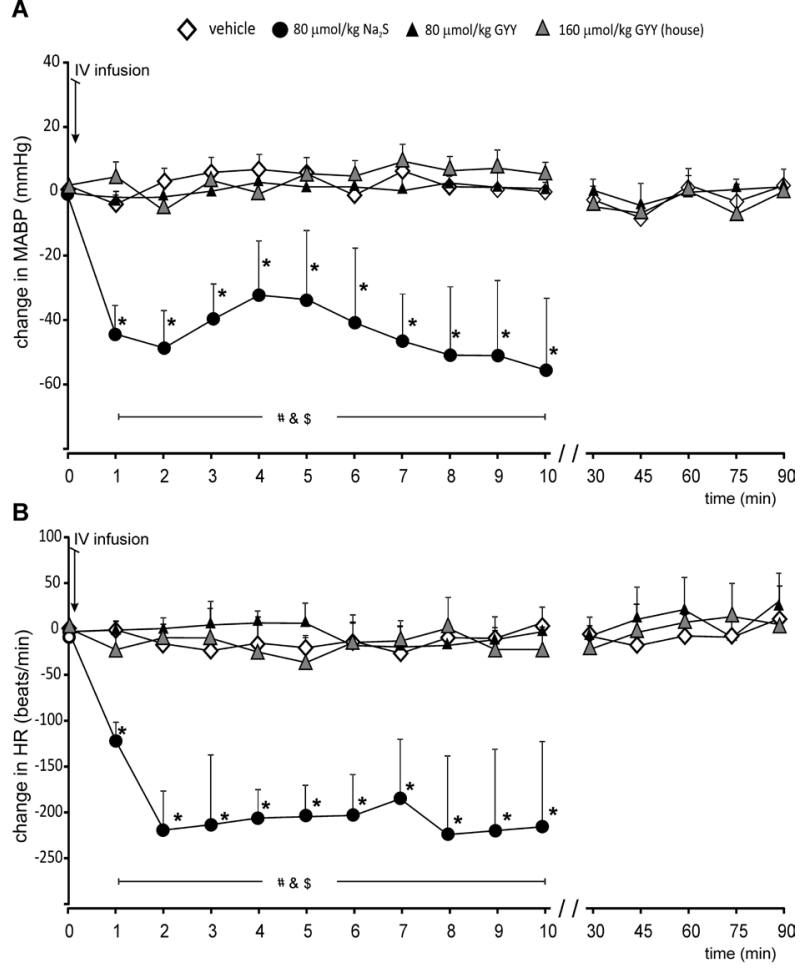

Figure 2. Changes in (A) mean arterial blood pressure (MABP, $\mathrm{mmHg}$ ), and (B) heart rate ( $\mathrm{HR}$, beats/min) after intravenous administration of investigated compounds (IV infusion)

${ }^{*} P<0.05$ - vs baseline. ${ }^{S} P<0.05$ - vehicle vs $80 \mu \mathrm{mol} / \mathrm{kg}$ of $\mathrm{Na}_{2} \mathrm{~S}$ series. $\# P<0.05-80 \mu \mathrm{M}$ GYY4137 series vs $80 \mu \mathrm{mol} / \mathrm{kg}$ of $\mathrm{Na}_{2} \mathrm{~S}$ series. $\& P<0.05-160 \mu \mathrm{M}$ GYY4137 series vs $80 \mu \mathrm{mol} / \mathrm{kg}$ of $\mathrm{Na}_{2} \mathrm{~S}$ series (ANOVA, followed by Tukey's post hoc test).

buffer $(200 \mathrm{mM})$ were prepared fresh before the experiment and stored in the dark, at room temperature in closed Falcon tubes. Aliquots from stock solutions were mixed with $100 \mu \mathrm{M}$ DTNB (Sigma-Aldrich) at $15 \mathrm{~min}$ intervals (up to $90 \mathrm{~min}$ ) and after $13 \mathrm{hrs}$. The absorbance at $412 \mathrm{~nm}$ was measured. The concentration of $\mathrm{H}_{2} \mathrm{~S}$ was calculated using the following extinction coefficient: $\varepsilon_{412 \mathrm{~nm}}=14100 \mathrm{M}^{-1} \mathrm{~cm}^{-1}$ (Nashef et al., 1977; Vasas et al., $2015)$

\section{RESULTS}

\section{Animal studies}

The effect of intravenous infusions of $\mathrm{Na}_{2} \mathrm{~S}$ and GYY4137

There were no significant differences in MABP and $\mathrm{HR}$ at baseline between the experimental series ( $\mathrm{Ta}-$ ble 1). Treatment with the vehicle $(n=6)$, GYY4137 (Sigma-Aldrich) at a dose of $80 \mu \mathrm{mol} / \mathrm{kg} \quad(\mathrm{n}=6)$ and GYY4137 (house) at a dose of $160 \mu \mathrm{mol} / \mathrm{kg}(\mathrm{n}=6) \mathrm{did}$ not affect MABP and HR. $\mathrm{Na}_{2} \mathrm{~S}$ at a dose of $80 \mu \mathrm{mol} /$ $\mathrm{kg}(\mathrm{n}=6)$ produced a significant decrease in MABP and $\mathrm{HR}$, and 3 out of 6 rats died within 10 minutes after the infusion due to significant hypotension (Fig. 2).

The effect of intraperitoneal infusions of $\mathrm{Na}_{2} \mathrm{~S}$ and GYY4137

There were no significant differences in MABP and $\mathrm{HR}$ at baseline between the experimental series ( $\mathrm{Ta}$ ble 1). Rats treated with the vehicle $(n=6)$ and GYY4137 (Sigma-Aldrich) at a dose of $140 \mu \mathrm{mol} / \mathrm{kg}(\mathrm{n}=5)$ showed no significant change in MABP and HR. Rats treated
Table 1. Baseline mean arterial blood pressure (MABP, $\mathrm{mmHg}$ ) and heart rate (HR, beats/min) in the experimental series in WKY rats.

\begin{tabular}{lll}
\hline Series & MABP & HR \\
\hline WKY (Intravenous) & & \\
$20 \%$ DMSO (controls) & $79.3 \pm 2.1$ & $319 \pm 10$ \\
$80 \mu \mathrm{mol} / \mathrm{kg} \mathrm{Na}$ S & $80.5 \pm 3.2$ & $327 \pm 11$ \\
$80 \mu \mathrm{mol} / \mathrm{kg} \mathrm{GYY}$ & $80.7 \pm 2.2$ & $316 \pm 9$ \\
$160 \mu \mathrm{mol} / \mathrm{kg} \mathrm{GYY}$ & $78.8 \pm 3.9$ & $311 \pm 18$ \\
\hdashline $\mathrm{WKY}$ (Intraperitoneal) & & \\
$20 \% \mathrm{DMSO}$ (controls) & $80.5 \pm 2.0$ & $304 \pm 17$ \\
$70 \mu \mathrm{mol} / \mathrm{kg} \mathrm{Na}$ S & $81.2 \pm 3.2$ & $309 \pm 19$ \\
$140 \mu \mathrm{mol} / \mathrm{kg} \mathrm{GYY}$ & $81.7 \pm 2.5$ & $331 \pm 16$ \\
\hline
\end{tabular}

with $\mathrm{Na}_{2} \mathrm{~S}$ at a dose of $70 \mu \mathrm{mol} / \mathrm{kg}(\mathrm{n}=5)$ showed a significant decrease in MABP for the first three minutes after the infusion and in HR for ten minutes after the infusion (Fig. 3).

\section{Chemistry study on GYY4137}

Stability of GYY4137 in buffers and rat plasma/half life

In the buffers at $\mathrm{pH}$ of 7.4 and 5.5, as well as in rat plasma, only one signal corresponding to GYY4137 was observed in ${ }^{31} \mathrm{P}$ NMR at $89.0 \mathrm{ppm}$, showing no changes in NMR spectra of GYY4137 during 18 hrs of observation. In contrast, a rapid and complete decomposition of GYY4137 occurred in buffers at $\mathrm{pH}$ 2.0, leading to formation of 3 new species, which manifested as three signals at 93.7, 81.7 and $66.9 \mathrm{ppm}$ in ${ }^{31} \mathrm{P}$ NMR spectra (Fig. 4).

A

$$
\diamond \text { vehicle } \quad \mathbf{O}^{70 \mu \mathrm{mol} / \mathrm{kg} \mathrm{Na}, S} \quad \Delta 140 \mu \mathrm{mol} / \mathrm{kg} \text { GW }
$$
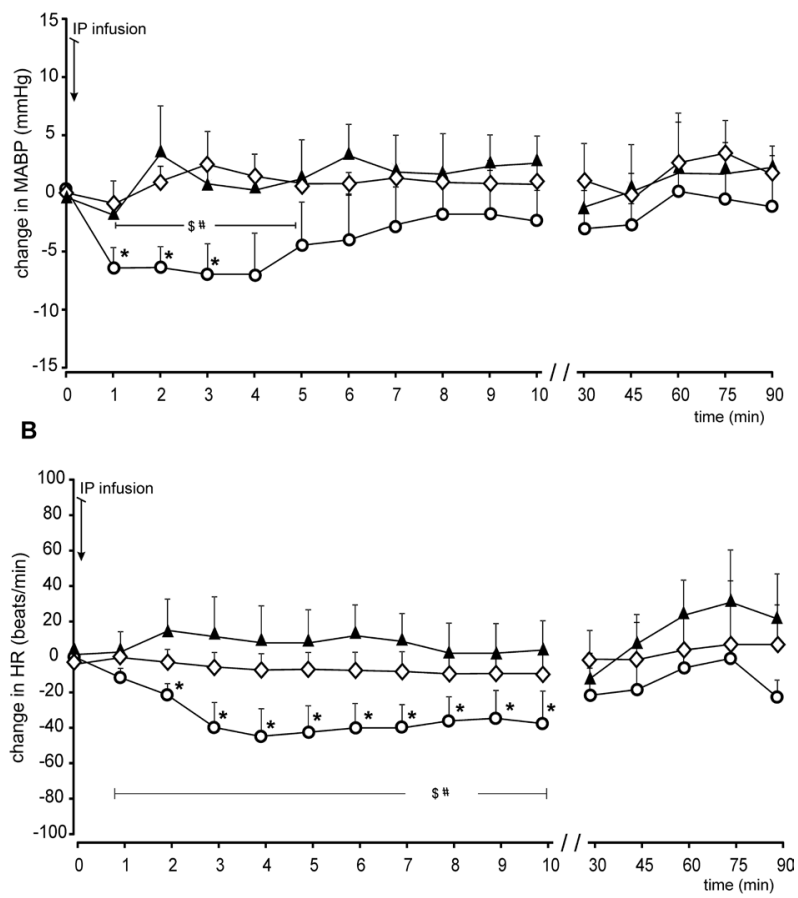

Figure 3. Changes in (A) mean arterial blood pressure (MABP, $\mathrm{mmHg}$ ), and (B) heart rate ( $\mathrm{HR}$, beats/min) after intraperitoneal administration of investigated compounds (IP infusion) ${ }^{*} P<0.05$ - vs baseline. ${ }^{\$} P<0.05$ - vehicle vs $70 \mu \mathrm{mol} / \mathrm{kg}$ of $\mathrm{Na}_{2} \mathrm{~S}$ series. $\# P<0.05-140 \mu \mathrm{mol} / \mathrm{kg}$ of GYY4137 series vs $70 \mu \mathrm{mol} / \mathrm{kg}$ of $\mathrm{Na}_{2} \mathrm{~S}$ series (ANOVA, followed by Tukey's post hoc test). 
A

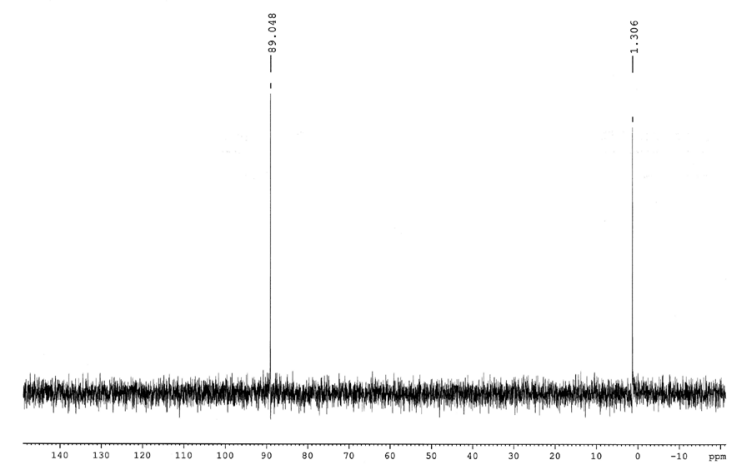

B

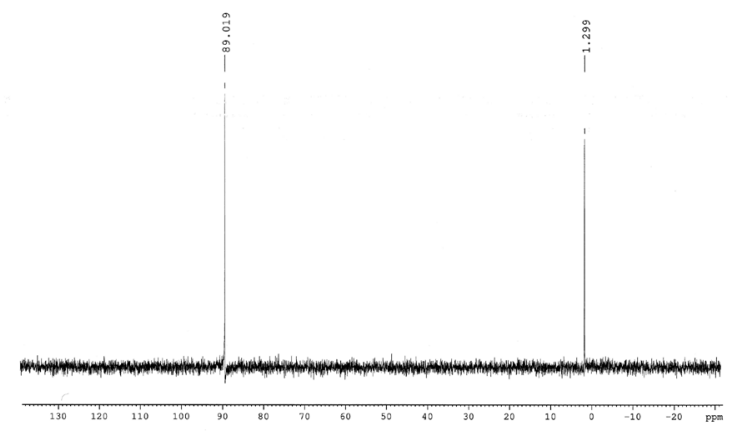

D

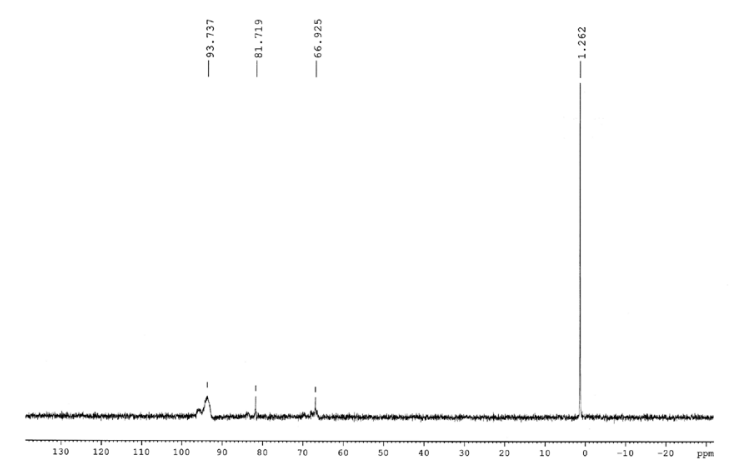

Figure 4. ${ }^{31}$ P NMR spectra of GYY4137 in buffers and rat plasma/ half-life (A: buffer pH 7.4; B: buffer pH 5.5; C: rat plasma pH 7.4; D: buffer $\mathrm{pH}$ 2.0)

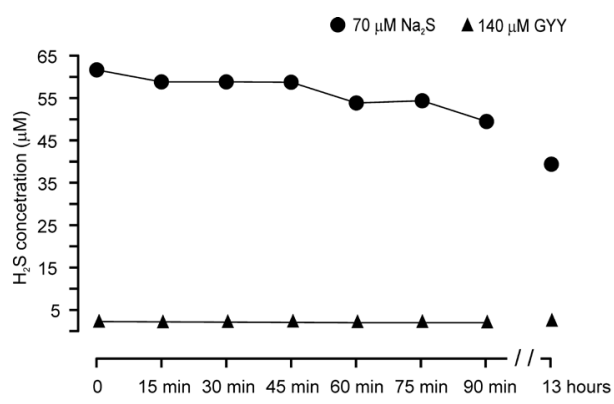

tim

Figure 5. $\mathrm{H}_{2} \mathrm{~S}$ release from $\mathrm{Na}_{2} \mathrm{~S}(70 \mu \mathrm{M})$ and GYY4137 $(140 \mu \mathrm{M})$ in Tris/HCl buffer (pH 7.4) determined by the DTNB assay.

$\mathrm{H}_{2} \mathrm{~S}$ release from $\mathrm{Na}_{2} \mathrm{~S}$ and GYY4137

The concentration of $\mathrm{H}_{2} \mathrm{~S}$ in $70 \mu \mathrm{M} \mathrm{Na} \mathrm{Na}_{2}$ solution 15 minutes after preparation was $61.5 \mu \mathrm{M}$, slowly decreasing over time to a value of $49.4 \mu \mathrm{M}$ in the 90 th min and reaching the concentration of $39.1 \mu \mathrm{M}$ after $13 \mathrm{hrs}$. In contrast, a very low amount of $\mathrm{H}_{2} \mathrm{~S}$ was released from $140 \mu \mathrm{M}$ GYY4137. There was a stable $\mathrm{H}_{2} \mathrm{~S}$ concentration of $<2 \mu \mathrm{M}$ during the first $90 \mathrm{~min}$. After $13 \mathrm{hrs}$ the concentration of $\mathrm{H}_{2} \mathrm{~S}$ in GYY4137 solution reached $2.3 \mu \mathrm{M}$ (Fig. 5).

\section{DISCUSSION}

We found that parenteral $\mathrm{Na}_{2} \mathrm{~S}$, a fast-releasing $\mathrm{H}_{2} \mathrm{~S}$ donor, but not GYY4137, a slow-releasing $\mathrm{H}_{2} \mathrm{~S}$ donor, lowers arterial blood pressure in rats. The lack of hemodynamic effects of parenteral GYY4137 seems to result from its high stability at plasma $\mathrm{pH}$.

Increasing research points to an important role of $\mathrm{H}_{2} \mathrm{~S}$ and its derivatives in the control of numerous biological systems (Wang, 2012), and several studies suggest that $\mathrm{H}_{2} \mathrm{~S}$ donors may have a therapeutic potential in cardiovascular diseases, in particular in hypertension (Meng et al., 2014).

In the present study $\mathrm{Na}_{2} \mathrm{~S}$ given IP and IV produced a significant hypotensive effect. This is in line with previous studies (Drobna et al., 2014; Yoo et al., 2015). The smaller hypotensive effect of the $\mathrm{H}_{2} \mathrm{~S}$ donor given IP in comparison to IV administration resulted probably from the lower bioavailability of the compound after IP administration. Since IP administered drugs undergo first-pass metabolism, a significant portion of $\mathrm{H}_{2} \mathrm{~S}$ and its derivatives was likely metabolized by the liver sulfurtransferases which are involved in thiosulfate and sulfite conversions (Mishanina et al., 2015).

GYY4137 is a slow-releasing $\mathrm{H}_{2} \mathrm{~S}$ donor that was studied in several experimental settings, and several studies suggested its biological activity. For example, it was found that GYY4137 inhibits the development of hypertension (Li et al., 2008), atherosclerosis (Liu et al., 2013), myocardial ischemia (Lee et al., 2014) and cancer (Bucci et al., 2012). Some studies showed hypotensive ( $\mathrm{Li}$ et al., 2008) and vasorelaxant (Bucci et al., 2012; Chitnis et al., 2013; Wang et al., 2013) activity of GYY4137. For example, $\mathrm{Li}$ and coworkers found that IV administration of 
GYY4137 (26.6 to $133 \mu \mathrm{mol} / \mathrm{kg}$ BW) decreases BP in rats (Li et al., 2008).

Here, we found no hemodynamic effect of GYY4137 at a dose of $140 \mu \mathrm{mol} / \mathrm{kg} \mathrm{BW}$ given IP and of 80 and $160 \mu \mathrm{mol} / \mathrm{kg} \mathrm{BW}$ given IV, whereas $\mathrm{Na}_{2} \mathrm{~S}$ given at a half of GYY4137 dose $(70 \mu \mathrm{mol} / \mathrm{kg}$ IP and $40 \mu \mathrm{mol} / \mathrm{kg}$ IV) produced a significant decrease in BP. Discrepancies between the findings of $\mathrm{Li}$ at al. and our results may be caused by different experimental settings, such as a different strain of experimental rats or a different source of GYY4137.

Since in our experiments the commercially available GYY4137 failed to exert hemodynamic effects, we believed it could be caused by impurities which interfered with the GYY4137 action. Therefore, we obtained GYY4137 using a slightly modified literature procedure. The elaborated protocol provided the desired product, free of impurities, in a reproducible way with good yield, as a white, crystalline solid, as a 2:1 complex of GYY4137:DCM. However, again we did not find a significant hemodynamic effect of GYY4137 in rats.

Previously, GYY4137 was shown to be a slow releasing $\mathrm{H}_{2} \mathrm{~S}$ donor (Li et al., 2008; Feng et al., 2015), however, it is still unclear which conditions are needed for GYY4137 to release $\mathrm{H}_{2} \mathrm{~S}$. Lee et al. reported a sustained release of $\mathrm{H}_{2} \mathrm{~S}$ from GYY4137 by using the standard methylene blue method (Lee et al., 2011). This method may not be appropriate for measuring the release of $\mathrm{H}_{2} \mathrm{~S}$ from phosphorodithioates, since strong acidic conditions involved in this method accelerate GYY4137 hydrolysis and $\mathrm{H}_{2} \mathrm{~S}$ release (Bode \& Arnswald, 1962). Besides, methylene blue forms dimers and trimers that interfere with the absorbance measurement at 670, thereby violating the Beer's law and producing artificial readings (Yuan et al., 2015). Using the DTNB assay, Li and coworkers showed that the release of $\mathrm{H}_{2} \mathrm{~S}$ from GYY4137 $(1 \mathrm{mM})$ at $\mathrm{pH} 7.4$ and 8.5 in aqueous solution is $\sim 3$ $\mu \mathrm{M} / 25 \mathrm{~min}$. In contrast, at $\mathrm{pH} 3$ the releasing property was much greater i.e. $\sim 50 \mu \mathrm{M} / 25 \mathrm{~min}(\mathrm{Li}$ et al., 2008). Here, using the DTNB assay, we found that $13 \mathrm{hrs}$ of GYY4137 $(140 \mu \mathrm{M})$ incubation at $\mathrm{pH} 7.4$ produced 1-2 $\mu \mathrm{mol}$ of $\mathrm{H}_{2} \mathrm{~S}$, while two times lower concentration of $\mathrm{Na}_{2} \mathrm{~S}(70 \mu \mathrm{M})$ produced $60 \mu \mathrm{mol}$ of $\mathrm{H}_{2} \mathrm{~S}$. Therefore, the release of $\mathrm{H}_{2} \mathrm{~S}$ from GYY4137 at physiological $\mathrm{pH}$ seems negligible and may be within method error.

Kashfi and Olsen (Kashfi \& Olsen, 2013) noted that in the study by Li and coworkers (2008) GYY4137 was reported to be more potent than $\mathrm{NaHS}$ in relaxing rat aorta (EC50s 115.7 vs $274.1 \mu \mathrm{M}$, respectively). However, it is not clear how so little of $\mathrm{H}_{2} \mathrm{~S}$ from GYY4137 could be vasoactive. As mentioned above, 11 of $1 \mathrm{mM}$ of GYY4137 at $\mathrm{pH} 7.4$ releases less than $3 \mu \mathrm{mol}$ of $\mathrm{H}_{2} \mathrm{~S} / 25$ min. Therefore, $115 \mu \mathrm{M}$ GYY4137 releasing $\sim 0.3 \mu \mathrm{mol}$ of $\mathrm{H}_{2} \mathrm{~S}$ should be no more potent than $100 \mu \mathrm{M} \mathrm{H} \mathrm{H}_{2} \mathrm{~S}$ (as NaHS). In addition, $\mathrm{H}_{2} \mathrm{~S}$ formation from GYY4137 in buffer was measured with an amperometric sensor, whereas $\mathrm{H}_{2} \mathrm{~S}$ formation in plasma was not determined amperometrically, but was measured with the methylene blue method. It is unclear why the latter was used as it is associated with considerable artifact (Kashfi \& Olson, 2013). In this context, recently fluorescent probes were shown to be useful for evaluating $\mathrm{H}_{2} \mathrm{~S}$ donors (Chan et al., 2012; Lin \& Chang, 2012; Xuan et al., 2012). At neutral pH GYY4137 at a concentration of $\leq 200 \mu \mathrm{M}$ was found to release small amounts of $\mathrm{H}_{2} \mathrm{~S}$, near to the detection threshold $(\sim 1 \mu \mathrm{M})$ in the dansyl azide fluorescent assay (Park et al., 2013; Feng et al., 2015).

In our study, using NMR we checked the stability of GYY4137 and we found no hydrolysis of GYY4137 at
$\mathrm{pH} 7.4$ and 5.5. We found only the signal belonging to native GYY4137 in ${ }^{31} \mathrm{P}-\mathrm{NMR}$ spectra at $89 \mathrm{ppm}$. Similar behaviour of GYY4137 was recently observed by others (Alexander et al., 2015). The stability of a compound such as GYY4137 may be affected by several plasma enzymes. Therefore, we additionally checked the stability of GYY4137 in rat plasma. The results were similar to what we had found in buffers. Namely, we found only the signal that belongs to native GYY4137 in ${ }^{31} \mathrm{P}-\mathrm{NMR}$ spectra at 89 ppm, which proves the lack of structural changes of the molecule, and thus the lack of $\mathrm{H}_{2} \mathrm{~S}$ release under such conditions. In contrast, a rapid and complete decomposition of GYY4137, enabling the release of $\mathrm{H}_{2} \mathrm{~S}$, occurred at $\mathrm{pH} 2.0$ leading to production of 3 new species which manifested as three signals at 94.0, 82.0 and $67.2 \mathrm{ppm}$ that may belong to phosphoric acid derivatives; arylphosphonamidothioate and arylphosphonate (Alexander et al., 2015). Unfortunately, such pH is far from physiological $\mathrm{pH}$ of plasma or intracellular fluid.

It may be hypothesized, however, that GYY4137 may release $\mathrm{H}_{2} \mathrm{~S}$ in biologically relevant amounts when administered orally in humans or rats whose $\mathrm{pH}$ in the stomach ranges between 3 and 4 (Ward \& Coates, 1987). It is also possible that GYY4137 may release $\mathrm{H}_{2} \mathrm{~S}$ when exposed to the liver enzymatic processing, however, we did not find a hemodynamic effect of neither IV administered nor IP administered GYY4137, while IP given drugs undergo the liver first-pass metabolism. Finally, it is also possible that previously reported biological effects observed after administration of GYY4137 were not $\mathrm{H}_{2} \mathrm{~S}$-dependent but caused by GYY4137 itself or its metabolism products (Yuan \& Coates, 2015; Zheng et al., 2015).

In conclusion, we found that parenteral administration of GYY4137 does not affect hemodynamics in rats. This seems to be due to the high stability of GYY4137 at physiological pH. Using NMR, we showed no structural changes of GYY4137 in buffers at $\mathrm{pH} 7.4$ and 5.5 and in rat plasma, i.e. the lack of $\mathrm{H}_{2} \mathrm{~S}$ release. Therefore, it is likely that widely reported biological effects of GYY4137 are not $\mathrm{H}_{2} \mathrm{~S}$-dependent but may depend on GYY4137 itself. Since the release of $\mathrm{H}_{2} \mathrm{~S}$ from GYY4137 requires low $\mathrm{pH}$, the $\mathrm{H}_{2} \mathrm{~S}$-dependent biological effects of GYY4137 may be expected in tissues characterized by low $\mathrm{pH}$.

\section{Acknowledgements of financial support}

This study was supported by The National Science Centre of Poland under grant No 2016/22/E/ NZ5/00647.

\section{REFERENCES}

Alexander BE, Coles SJ, Fox BC, Khan TF, Maliszewski J, Perry A, Pitak MB, Whiteman M, Wood ME (2015) Investigating the generation of hydrogen sulfide from the phosphonamidodithioate slow-release donor GYY4137. Med Chem Comm 6: 1649-1655. doi 10.1039/ C5MD00170F

Bode H, Arnswald W (1962) Untersuchungen über substituierte Dithiophosphate - II. Mitteilung Bildung der Metall-Diäthyldithiophosphate und ihre Extrahierbarkeit aus mineralsauren Lösungen. $W Z$ Anal Chem 185: 179-201. doi 10.1007/BF00470785

Bucci M, Papapetropoulos A, Vellecco V, Zhou Z, Zaid A, Giannogonas P, Cantalupo A, Dhayade S, Karalis KP, Wang R, Feil R, Cirino G (2012) cGMP-dependent protein kinase contributes to hydrogen sulfide-stimulated vasorelaxation. PLoS One 7: e53319. doi 10.1371/ journal.pone.0053319

Chan J, Dodani SC, Chang CJ (2012) Reaction-based small-molecule fluorescent probes for chemoselective bioimaging. Nat Chem 4: 973984. doi 10.1038/nchem.1500 
Chitnis MK, Njie-Mbye YF, Opere CA, Wood ME, Whiteman M, Ohia SE (2013) Pharmacological actions of the slow release hydrogen sulfide donor GYY4137 on phenylephrine-induced tone in isolated bovine ciliary artery. Exp Eye Res 116: 350-354. doi 10.1016/j. exer.2013.10.004

Drobná M, Misak A, Holland T, Kristek F, Grman M, Tomasova L, Berenyiova A, Cacanyiova S, Ondrias K (2015) Captopril partially decreases the effect of $\mathrm{H}(2) \mathrm{S}$ on rat blood pressure and inhibits $\mathrm{H}(2) \mathrm{S}$-induced nitric oxide release from S-nitrosoglutathione. Physiol Res 64: 479-86

Feng W, Teo XY, Novera W, Ramanujulu PM, Liang D, Huang D, Moore PK, Deng LW, Dymock BW (2015) Discovery of new H2S releasing phosphordithioates and 2,3-dihydro-2-phenyl2-sulfanylenebenzo[d][1,3,2]oxazaphospholes with improved antiproliferative activity. J Med Chem 58: 6456-6480. doi 10.1021/acs. jmedchem.5b00848

Kashfi K, Olson KR (2013) Biology and therapeutic potential of hydrogen sulfide and hydrogen sulfide-releasing chimeras. Biochem Pharmacol 85: 689-703. doi 10.1016/j.bcp.2012.10.019

Lee ZW, Teo XY, Tay EY, Tan CH, Hagen T, Moore PK, Deng LW (2014) Utilizing hydrogen sulfide as a novel anti-cancer agent by targeting cancer glycolysis and $\mathrm{pH}$ imbalance. $\mathrm{Br} J$ Pharmacol 171: 4322-4336. doi 10.1111/bph.12773

Lee ZW, Teo XY, Tay EY, Tan CH, Hagen T, Moore PK, Deng LW (2011) The slow-releasing hydrogen sulfide donor, GYY4137, exhibits novel anti-cancer effects in vitro and in vivo. PLoS One 6: e21077. doi $10.1111 /$ bph.12773

Li L, Whiteman M, Guan YY, Neo KL, Cheng Y, Lee SW, Zhao Y, Baskar R, Tan CH, Moore PK (2008) Characterization of a novel, water-soluble hydrogen sulfide-releasing molecule (GYY4137): new insights into the biology of hydrogen sulfide. Circulation 117: 23512360. doi 10.1161/CIRCULATIONAHA.107.753467

Lilyanna S, Peh MT, Liew OW, Wang P, Moore PK, Richards AM, Martinez EC (2015) GYY4137 attenuates remodeling, preserves cardiac function and modulates the natriuretic peptide response to ischemia. J Mol Cell Cardiol 87: 27-37. doi 10.1016/j.yjmcc.2015.07.028

Lin VS, Chang CJ (2012) Fluorescent probes for sensing and imaging biological hydrogen sulfide. Curr Opin Chem Biol 16: 595-601. doi 10.1016/j.cbpa.2012.07.014

Liu Z, Han Y, Li L, Lu H, Meng G, Li X, Shirhan M, Peh MT, Xie L, Zhou S, Wang X, Chen Q, Dai W, Tan CH, Pan S, Moore PK, Ji Y (2013) The hydrogen sulfide donor, GYY4137, exhibits antiatherosclerotic activity in high fat fed apolipoprotein $\mathrm{E}(-/-)$ mice. $\mathrm{Br}$ J Pharmacol 169: 1795-809. doi 10.1111/bph.12246

Lohninger L, Tomasova L, Praschberger M, Hintersteininger M, Erker T, Gmeiner BM, Laggner H (2015) Hydrogen sulphide induces HIF- $1 \alpha$ and Nrf2 in THP-1 macrophages. Biochimie 112: 187-195. doi 10.1016/j.biochi.2015.03.009

Martelli A, Testai L, Citi V, Marino A, Bellagambi FG, Ghimenti S, Breschi MC, Calderone V (2014) Pharmacological characterization of the vascular effects of aryl isothiocyanates: is hydrogen sulfide the real player? Vascul Pharmacol 60: 32-41. doi 10.1016/j. vph.2013.11.003

Meng G, Ma Y, Xie L, Ferro A, Ji Y (2015) Emerging role of hydrogen sulfide in hypertension and related cardiovascular diseases. $\mathrm{Br} \mathrm{J}$ Pharmacol 172: 5501-5511. doi 10.1111/bph.12900

Mishanina TV, Libiad M, Banerjee R (2015) Biogenesis of reactive sulfur species for signaling by hydrogen sulfide oxidation pathways. Nat Chem Biol 11: 457-464. doi 10.1038/nchembio
Nashef AS, Osuga DT, Feeney RE (1977) Determination of hydrogen sulfide with 5,5'-dithiobis-(2-nitrobenzoic acid), N-ethylmaleimide, and parachloromercuribenzoate. Anal Biochem 79: 394-405. doi 10.1016/0003-2697(77)90413-4

Park CM, Zhao Y, Zhu Z, Pacheco A, Peng B, Devarie-Baez NO, Bagdon P, Zhangb H, Xian M (2013) Synthesis and evaluation of phosphorodithioate-based hydrogen sulfide donors. Mol Biosyst 9: 2430-2434. doi 10.1039/C3MB70145J

Shen X, Pattillo CB, Pardue S, Bir SC, Wang R, Kevil CG (2011) Measurement of plasma hydrogen sulfide in vivo and in vitro. Free Radic Biol Med 50: 1021-1031. doi 10.1016/j.freeradbiomed.2011.01.025

Sikora M, Drapala A, Ufnal M (2014) Exogenous hydrogen sulfide causes different hemodynamic effects in normotensive and hypertensive rats via neurogenic mechanisms. Pharmacol Rep 66: 751-758. doi 10.1016/j.pharep.2014.04.004

Tomasova L, Dobrowolski L, Jurkowska H, Wróbel M, Huc T, Ondrias K, Ostaszewski R, Ufnal M (2016) Intracolonic hydrogen sulfide lowers blood pressure in rats. Nitric Oxide 60: 50-58. doi 10.1016/j. niox.2016.09.007

Ufnal M, Sikora M, Szczepanska-Sadowska E (2008) Interleukin-1 receptor antagonist reduces the magnitude of the pressor response to acute stress. Neurosci Lett 448: 47-51. doi 10.1016/j.neulet.2008.10.010

Vasas A, Dóka É, Fábián I, Nagy P (2015) Kinetic and thermodynamic studies on the disulfide-bond reducing potential of hydrogen sulfide. Nitric Oxide 46: 93-101. doi 10.1016/j.niox.2014.12.003

Wallace JL, Wang R (2015) Hydrogen sulfide-based therapeutics: exploiting a unique but ubiquitous gasotransmitter. Nat Rev Drug Discov 14: 329-345. doi 10.1016/j.niox.2014.12.003

Wang R (2012) Physiological implications of hydrogen sulfide: a whiff exploration that blossomed. Physiol Rev 92: 791-896. doi 10.1152/ physrev.00017.2011

Wang K, Ahmad S, Cai M, Rennie J, Fujisawa T, Crispi F, Baily J, Miller MR, Cudmore M, Hadoke PW, Wang R, Gratacós E, Buhimschi IA, Buhimschi CS, Ahmed A (2013) Dysregulation of hydrogen sulfide producing enzyme cystathionine $\gamma$-lyase contributes to maternal hypertension and placental abnormalities in preeclampsia. Circulation 127: 2514-2522. doi 10.1161/CIRCULATIONAHA

Ward FW, Coates ME (1987) Gastrointestinal pH measurement in rats: influence of the microbial flora, diet and fasting. Lab Anim 21: 216222. doi 10.1258/002367787781268693

Xuan W, Sheng C, Cao Y, He W, Wang W (2012) Fluorescent probes for the detection of hydrogen sulfide in biological systems. Angew Chem Int Ed Engl 51: 2282-2284. doi 10.1002/anie.201107025

Yoo D, Jupiter RC, Pankey EA, Reddy VG, Edward JA, Swan KW, Peak TC, Mostany R, Kadowitz PJ (2015) Analysis of cardiovascular responses to the H2S donors $\mathrm{Na} 2 \mathrm{~S}$ and $\mathrm{NaHS}$ in the rat. Am J Physiol Heart Circ Physiol 309: H605-H614. doi 10.1152/ajpheart.00171.2015

Yuan S, Patel RP, Kevil CG (2015) Working with nitric oxide and hydrogen sulfide in biological systems. Am J Physiol Lung Cell Mol Physiol 308: L403-L415. doi 10.1152/ajplung.00327.2014

Zheng Y, Ji X, Ji K, Wang B (2015) Hydrogen sulfide prodrugs-a review. Acta Pharm Sin B 5: 367-377. doi 10.1016/j.apsb.2015.06.004 